IOSR Journal of Engineering (IOSRJEN)

e-ISSN: 2250-3021, p-ISSN: 2278-8719

Vol. 3, Issue 5(May. 2013), ||V4 || PP 01-08

\title{
Effects of Misalignment in Cylindrical Roller Bearings on Contact between Roller and Inner Ring
}

\author{
Xintao Xia, Yantao Shang, Shichao Zhu \\ College of Mechatronical Engineering, Henan University of Science and Technology, Luoyang 471003, China
}

Abstract: Misalignment of roller has remarkable effects on the life span of bearings. Taking a cylindrical roller bearing N1015 as a research object, the contact stress between the roller and the raceway is studied by means of ANSYS in order to determine reasonably the angle of misalignment of roller. The results show that under the given load the misalignment of roller should be controlled in an appropriate range. Otherwise, the contact stresses between the roller and the raceway increase observably and the distribution of the contact stresses presents a complex asymmetry and nonuniformity.

Keywords: Cylindrical roller, Logarithmic curve generatrix, Misalignment of roller, Contact stress, ANSYS

\section{INTRODUTION}

Rolling bearing is the important base part in the mechanical manufacturing and equipment field and is widely used in various kinds of areas. Cylindrical roller bearing is usually used in sustaining of shaft. Due to the different coaxiality of bearing seat, bending deformation of shaft, inclination of inner ring, inclination of outer ring and so on, the aslant between roller and ring raceway will have significantly affected on the performance and service life of bearing. So, the research about the misalignment of roller is necessary [1-3].

The axes of roller of cylindrical roller with logarithmic curve generatrix coincide with $\mathrm{x}$-axis and y-axis in axial and radical direction. The logarithmic curve generatrix is vertical symmetry and the symmetry lines coincide with $y$-axis, as shown in Figure 1. The misalignment of roller is that the axis of cylindrical roller does not parallel the axis of ring raceway of bearing and there is an angle between them, as shown in Figure 2 [4-11].

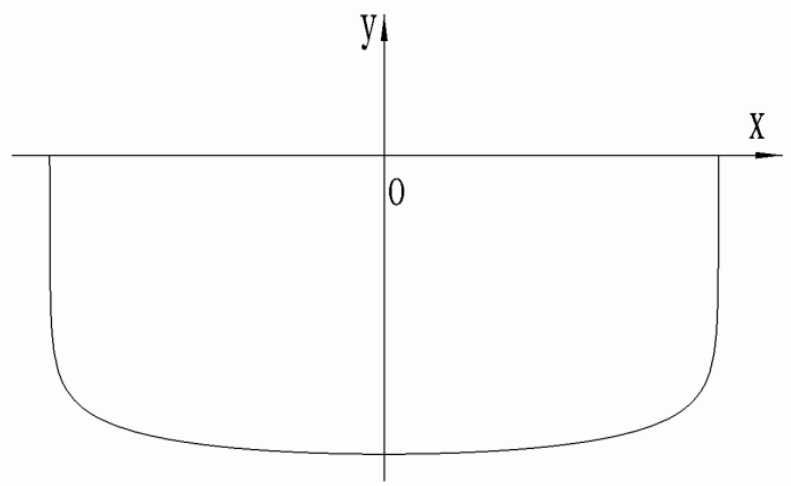

Fig. 1 Logarithmic curve generatrix of convexity roller bearing

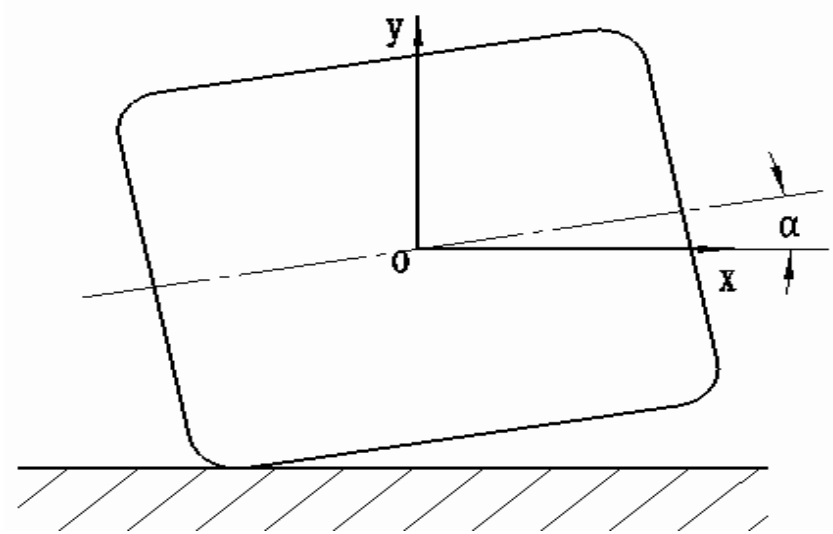

Fig. 2 Schematic diagram of misalignment-roller with logarithmic curve generatrix 


\section{FINITE ELEMENT MODEL OF CYLINDRICAL ROLLING BEARING}

\subsection{Technical Parameter of Bearing}

The technical parameters of the cylindrical roller bearing N1015 are shown in Table 1.

Table 1. Technical parameter

\begin{tabular}{ll}
\hline Parameter & Parameter value \\
\hline Bore diameter of bearing, $\mathrm{d} / \mathrm{mm}$ & 75 \\
Outside diameter of bearing, $\mathrm{D} / \mathrm{mm}$ & 115 \\
Thickness of ring, T/mm & 5 \\
Width of ring, $\mathrm{W} / \mathrm{mm}$ & 20 \\
Diameter of roller, $\Phi / \mathrm{mm}$ & 10 \\
Length of roller, $\mathrm{L} / \mathrm{mm}$ & 11 \\
Number of roller, N & 22 \\
Poisson ratio of bearing element material, v & 0.3 \\
Elastic modulus of bearing element material, E/GPa & 208 \\
\hline
\end{tabular}

\subsection{Crowning design}

The convexity equation of roller with logarithmic curve generatrix is expressed as

$$
y=2 \frac{\left(1-v^{2}\right) Q_{\max }}{\pi E L_{\mathrm{we}}} \ln \frac{1}{1-\left(2 x / L_{\mathrm{we}}\right)^{2}}
$$

where $y$ and $x$ are respectively logarithm function curve and its argument; $-L_{\mathrm{we}} / 2<x<L_{\mathrm{we}} / 2 ; v$ and $E$, in turn, are poisson ratio of bearing element materia and elastic modulus of bearing element material; $Q_{\max }$ is the maximum loading beared by roller; $L_{\mathrm{we}}$ is effective length of roller; $L_{\mathrm{we}}=\mathrm{L}_{w}-2 r, r$ is fillet radius in the roller end. $L_{w}$ is length of roller.

The maximum loading beared by roller is:

$$
Q_{\max }=\frac{4.08 F_{\mathrm{r}}}{Z}
$$

where $F_{\mathrm{r}}$ and $Z$ are respectively radial load beared by outer ring raceway and number of rollers.

The modeling of the roller with logarithmic curve generatrix, the logarithmic curve generatrix is not created directly, so the modeling could be created by Ansys Parameter Design Language, whose core contents are macro, parameter, loop program and conditional statements.

The part of APDL command stream of N1015 cylindrical rolling bearing is following:

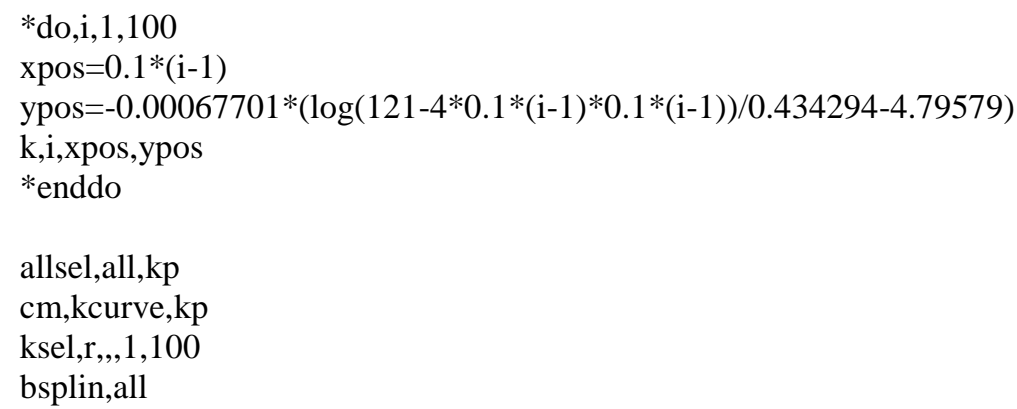

\subsection{Meshing}

In order to reduce computing time, one hand, the model of one-half roller at the bottom of the bearing that bears the maximum load is created; on the other hand, the chamfers of the inner and outer rings and the radial clearance are ignored. The Solid 45 is adopted to mesh the model. The meshes of the contact part of the roller and the inner and outer rings are refined to enhance the computing accuracy. The length of the grid along 
the axial direction is $0.07 \mathrm{~mm}$. Because the side length of the finite element model mesh is, particularly, less than half of the size of the minor semi-axis, the calculation results are precise enough. The half-width size of the contact area is $0.15 \mathrm{~mm}$ and the size of the finite element model is suitable, as shown in Figure 3.

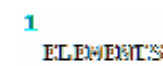

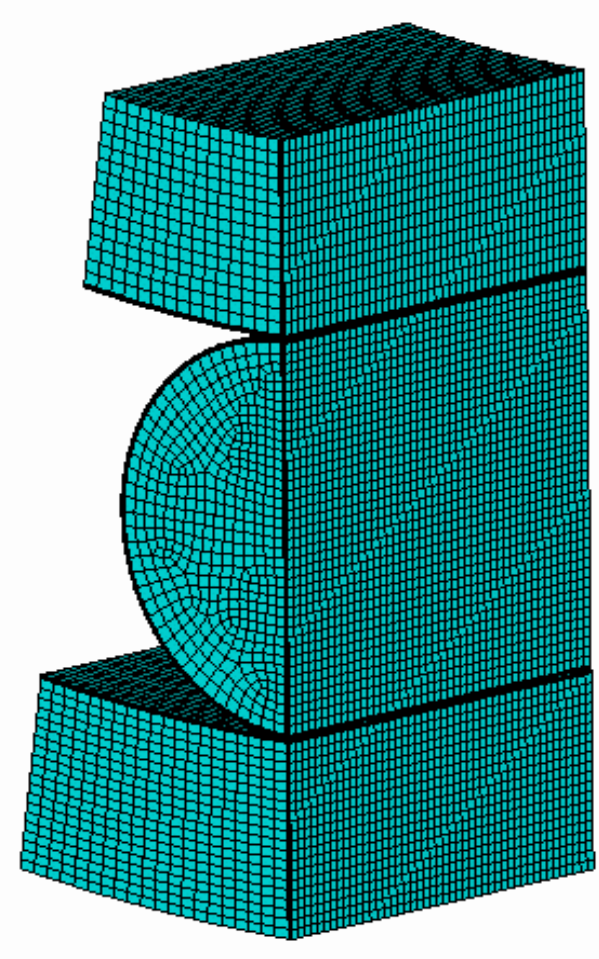

Fig. 3 Finite element model

\section{$\mathbf{N}$}

TEE .X. . X.K.

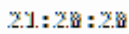

\subsection{Creation of Contact Pair}

The creation of the contact pair and the setting of the contact parameters are crucial issues on contact analysis [1, 4-6, 8-11]. Considering the inner and outer rings whose surfaces are bigger and stiffness is higher than the roller, the inner and outer rings are set as target surfaces and the roller is set as a contact surface. Then, the contact pairs are created respectively. Both the contact stiffness coefficient and the tolerance of penetration are key contact parameters. The smaller contact stiffness coefficient is favorable to be convergent. However, the bigger contact stiffness coefficient is favorable to improve the precision. By many times of calculation, the contact stiffness coefficient is set to 1.5 and the tolerance of penetration is set by a default value.

\subsection{Loading}

Before the load and the constraint are applied, the nodal coordinate systems belonging to the middle plane of the roller are all converted to the cylindrical coordinates and the displacement of nodes of the middle plane of the roller along the circumferential direction are all constrained. Furthermore, a symmetry constraint is applied to the cross-section of the roller and all the degrees of freedoms of the outer surface of the outer ring nodes are constrained. The load is applied to the finite element model after the radial freedom of the inner surface of the inner ring is coupled.

\section{ANALYSIS OF RESULTS}

Through modeling, meshing, constraining, loading, and solving, the results of the surface stress of the roller are obtained by finite element analysis. The normal direction contact stress produced by the roller and the outer ring raceway is used to analyze the effect of misalignment of roller on the contact stress. The normal roller loaded $1 / 5$ of the dynamic load rating is analyzed and the results of contact stresses and the third principal stress distribution cloud chart is respectively as shown in Figure 4-5. When the abscissa $x_{1}$ takes the value $5.4 \mathrm{~mm}$ that corresponds to the surface of the middle part of the inner ring raceway, the contact stress takes the largest value 1349.9 MPa. When the value of the abscissa $x_{1}$ is greater than $5.4 \mathrm{~mm}$ or less than $5.4 \mathrm{~mm}$, the contact stress gradually decreases. Obviously, the stress is distributed uniformly at the middle of the outer ring raceway 


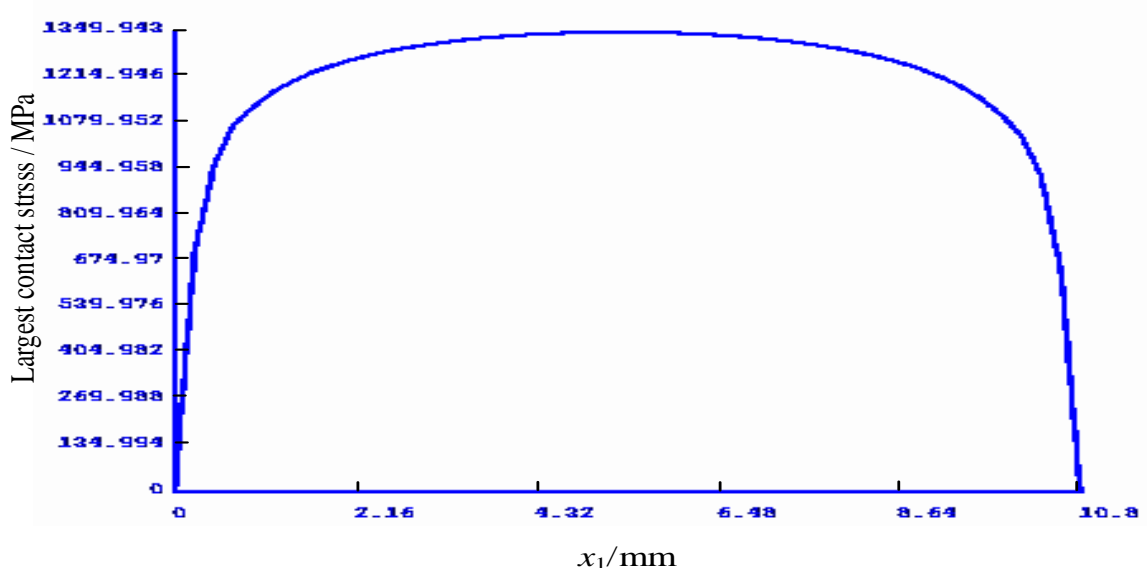

Fig.4 Largest contact stress curve between inner ring raceway and roller with misalignment $0^{\circ}$
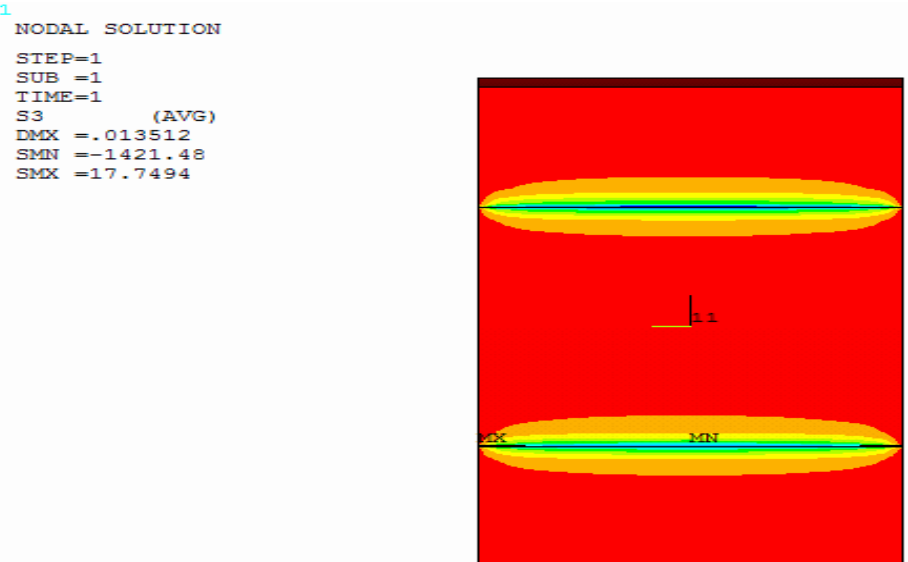

$\mathbf{N}$

APR 22 2013
$11: 50: 01$

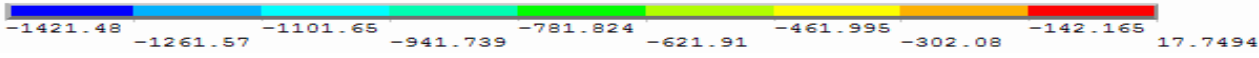

Fig.5 Minor principal stress distribution cloud chart between inner ring raceway and roller with misalignment $0^{\circ}$

The misalignment of roller is $0.01^{\circ}$ and the results of contact stresses and the third principal stress distribution cloud chart, in turn, are given in Figures 6-7. The misalignment of roller is $0.02^{\circ}-0.04^{\circ}$ and the results of contact stresses and the third principal stress distribution cloud chart, in turn, are given in Figures 813.

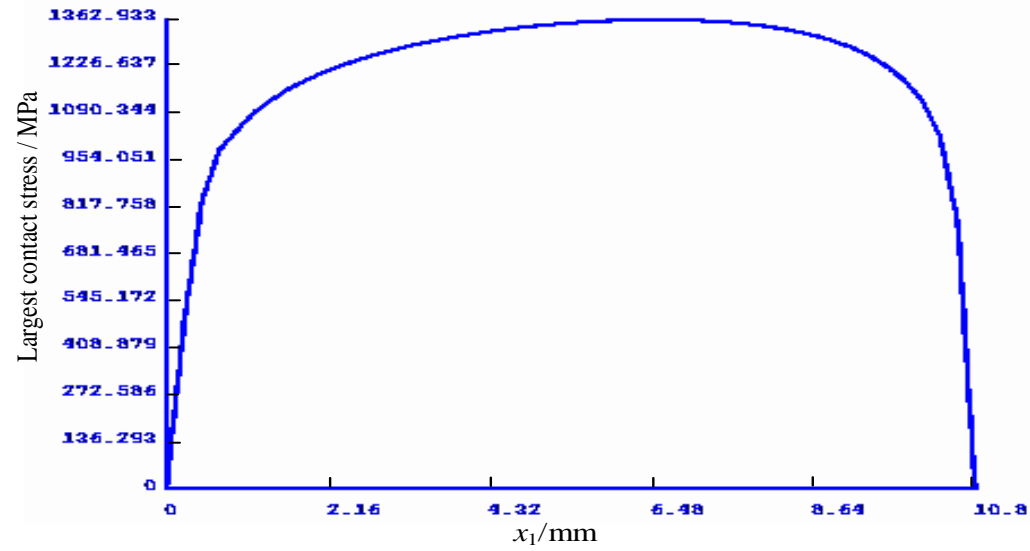

Fig.6 Largest contact stress curve between inner ring raceway and roller with misalignment $0.01^{\circ}$ 
NODAL SOLUTION

$\operatorname{STE} P=1$
$\operatorname{SUB}=1$

TIME $=1$

S3 (AVG)

$\mathrm{DMX}=.013787$

$\operatorname{SMX}=67,7605$

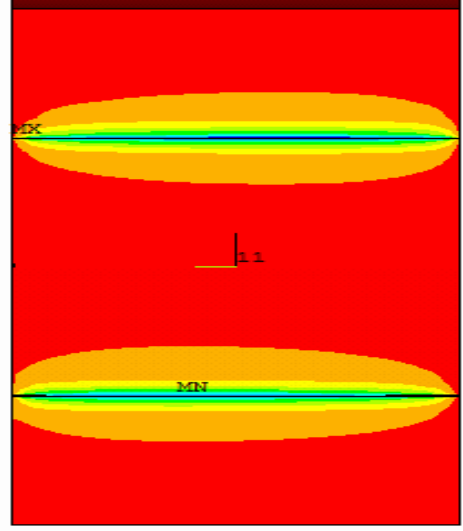

APR 222013

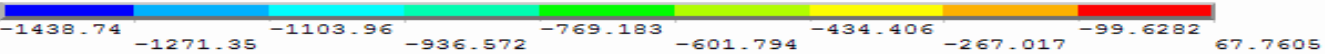

Fig.7 Minor principal stress distribution cloud chart between inner ring raceway and roller with misalignment $0.01^{\circ}$

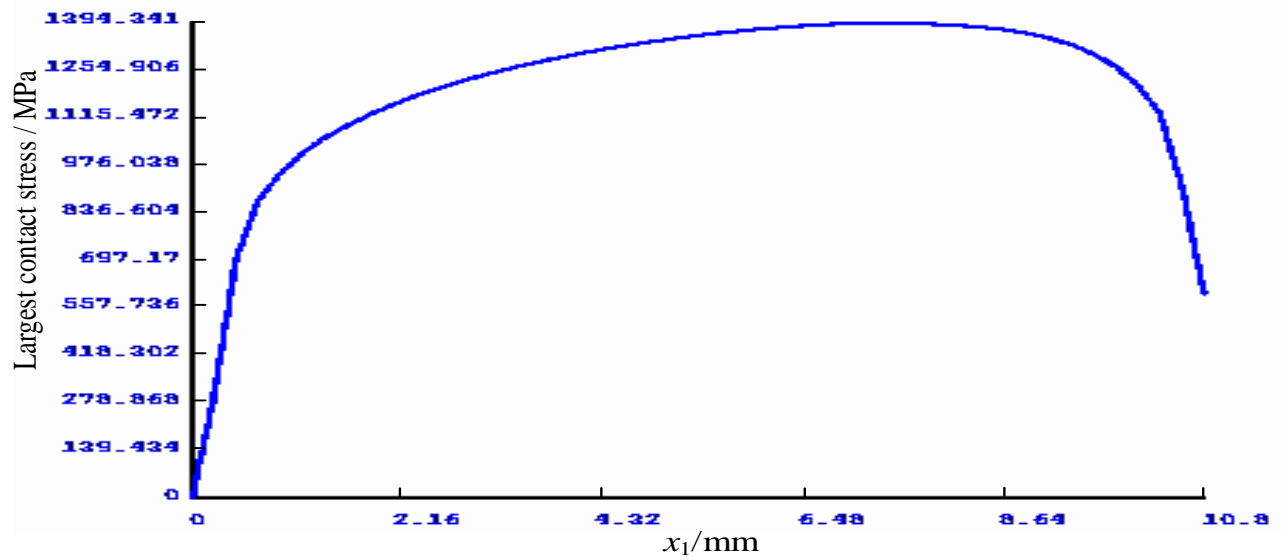

Fig. 8 Largest contact stress curve between inner ring raceway and roller with misalignment $0.02^{\circ}$

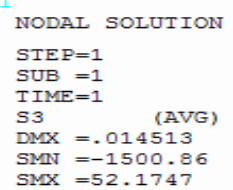

$\operatorname{SMX}=52.1747$

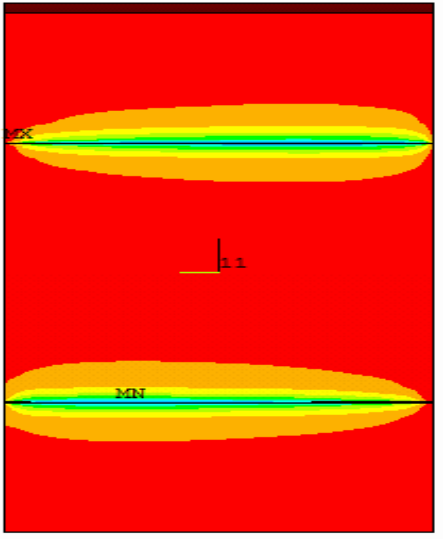

N

APR 22 2013

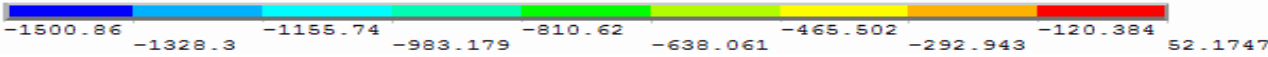

Fig.9 Minor principal stress distribution cloud chart between inner ring raceway and roller with misalignment $0.02^{\circ}$ 


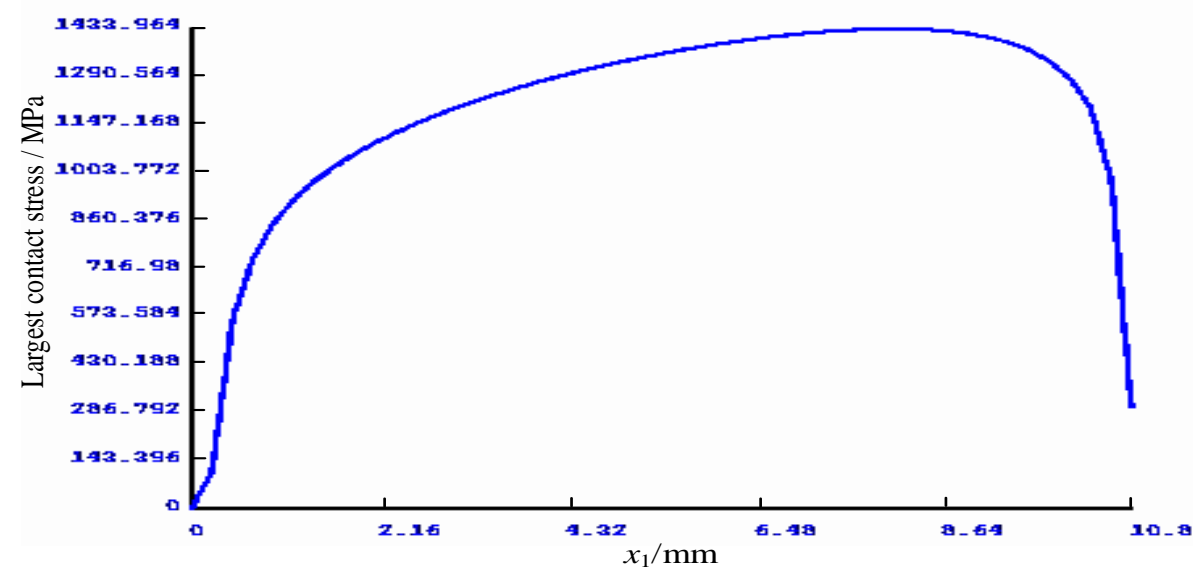

Fig.10 Largest contact stress curve between inner ring raceway and roller with misalignment $0.03^{\circ}$

$$
\begin{aligned}
& 1 \text { NODAL SOLUTION } \\
& \text { STEP }=1 \\
& \text { SUB }=1 \\
& \text { TIME }=1 \\
& \text { S3 } \quad \text { (AVG) } \\
& \text { DMX }=.01553 \\
& \text { SMN }=-1591.98 \\
& \text { SMX }=34.8219
\end{aligned}
$$

NN

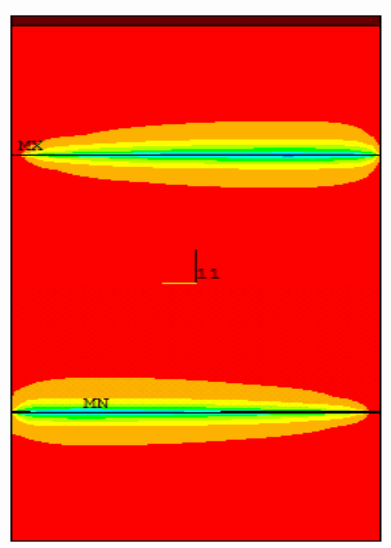

Fig.11 Minor principal stress distribution cloud chart between inner ring raceway and roller with misalignment $0.03^{\circ}$

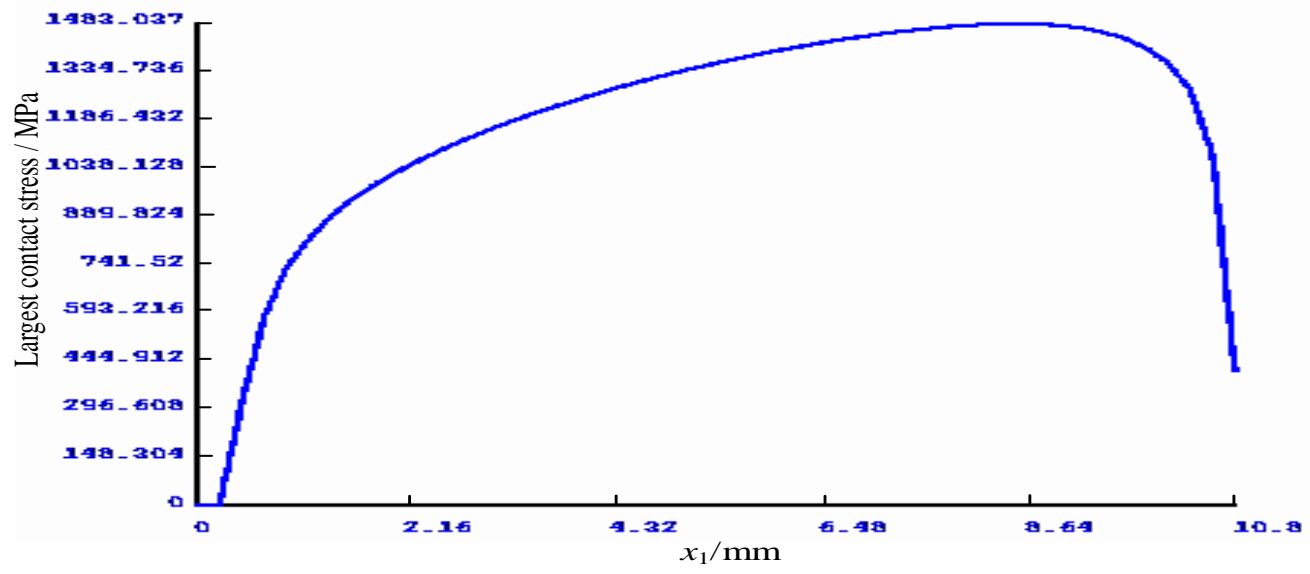

Fig.12 Largest contact stress curve between inner ring raceway and roller with misalignment $0.04^{\circ}$ 
NODAL SOLUTION

\section{$\mathbf{N}$}
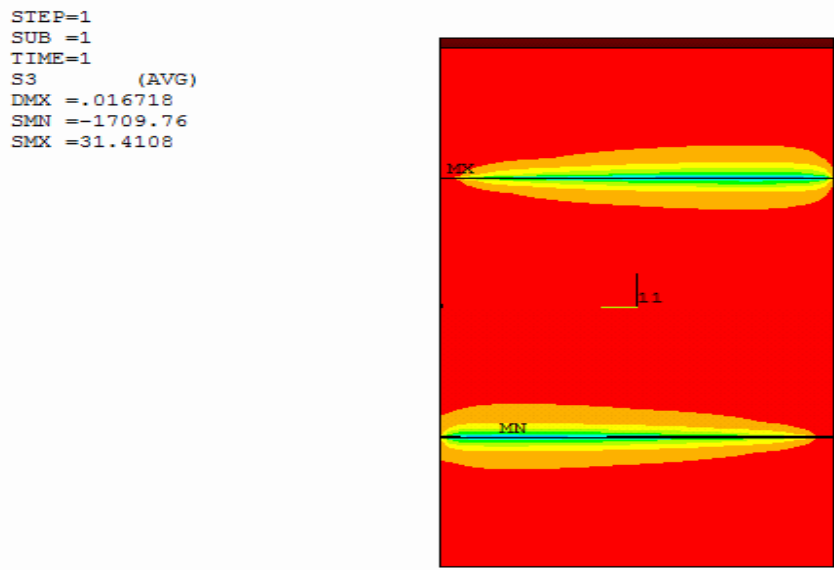

Fig.13 Minor principal stress distribution cloud chart between inner ring raceway and roller with misalignment $0.04^{\circ}$

It can be seen from Figures 6-13 that the maximum stress of the roller surface changes with the misalignment of the roller along the axial direction. The larger the misalignment error, the larger the maximum contact stress. If the misalignment error exceeds $0.03^{\circ}$, the value of the maximum stress increases sharply, as shown in Figure 10-11, showing the unusually additional contact stress gennerated by the assemble error.

In addition, when the misalignment error of the error is $0 \mathrm{~mm}$, the distribution of the contact stress is the most uniform, i.e., the maximum stress appears at $x_{1}=5.4 \mathrm{~mm}$ that corresponds to the surface of the middle part of the roller. With the increasing misalignment error, the location of the maximum stress gradually deviates from the middle part of the roller. If the misalignment error exceeds $0.03 \mathrm{~mm}$, the location of the maximum stress sharply deviates from the middle part of the roller, as shown in Figure 10-11, showing the abnormal contact stress distribution generated by the assemble error.

According to contact mechanics and rolling bearing theories, the unusually additional contact stress and abnormal contact stress distribution generated by the misalignment error belongs to an unfavorable condition. If the rolling bearing runs at great speed under such a condition, the axis of misalignment of the roller would appear skewed and the roller can therefore get stuck in two raceways, resulting in a safety incident.

As a result, in the process of misalignment of roller, the misalignment error must be controlled within an appropriate range, such as $0.03^{\circ}$ for the cylindrical roller bearing studied in this work, which are called the suitable upper bound of the misalignment error of the roller, as shown in Figure 14-15.

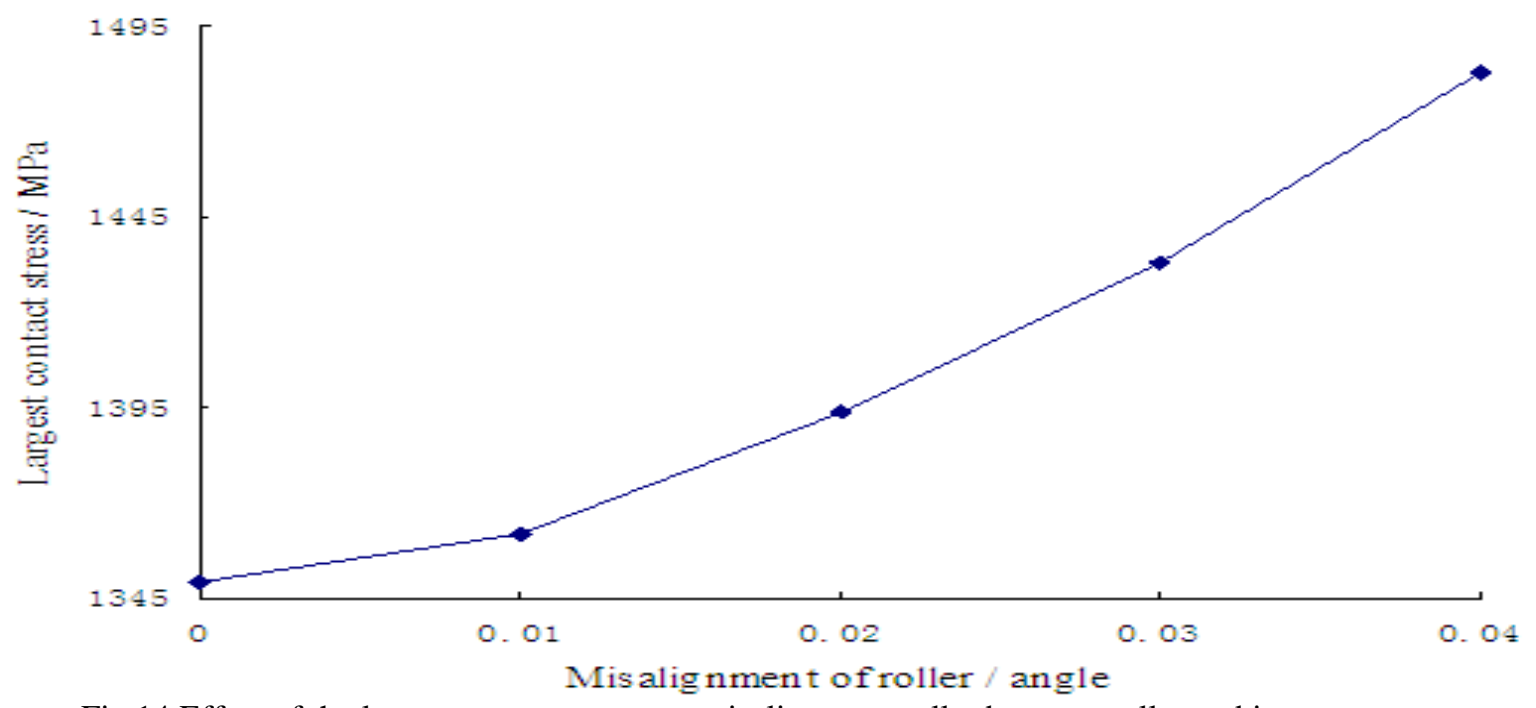

Fig.14 Effect of the largest contact stress on misalignment-roller between roller and inner raceway 


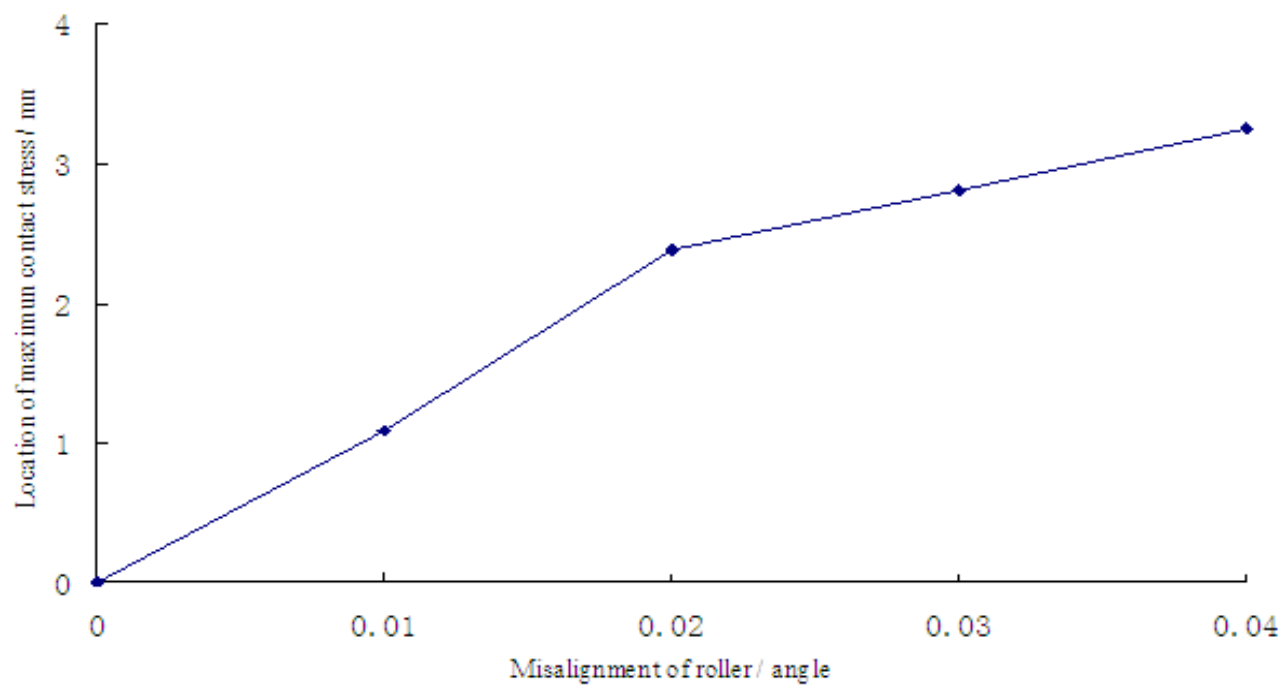

Fig.15 Influence of misalignment-roller on location maximum stress between roller and inner raceway

\section{CONCLUSIONS}

The given load corresponds to the suitable upper bound of the misalignment and with the increasing misalignment error, the contact stresses between the cylindrical roller and the inner raceway increases observably and the distribution of the contact stresses presents more complex asymmetry and nonuniformity. In the process of assembling bearing, the misalignment error must be controlled within appropriate range, such as $0.03^{\circ}$ for the cylindrical roller bearing studied in this work, which are called the suitable upper bound of the misalignment error of bearing.

\section{ACKNOWLEDGEMENTS}

The research is financed by the National Natural Science Foundation of China (Grant No. 5107 5123).

\section{REFERENCES}

[1]. Andrey, S., Hongrui, A., Yuan, J. H., Ruslan, P., \& Alexandr, D., Stressed state in the roller contact zone (area) and the bearing ring finite length. Advanced Materials Research, 482-484, 2012, 2017-2020.

[2]. Chandrasekara, M. C. S., \& Ramamohana, R. A., Mechanics and behaviour of hollow cylindrical members in rolling contact. Wear, 87, 1983, 287-296.

[3]. Chiu, Y. P., Hartnett, M. J., A numerical solution for the contact problem involving bodies with cylindrical surface considering cylinder effect. Journal of Tribology-Transactions of the ASME, 109, 1987, 479-486.

[4]. Demirhan, N., Kanber, B., Stress and displacement distribution on cylindrical roller bearing rings using FEM. Mechanics Based Design of Structures and Machines, 36, 2008, 86-102.

[5]. Hanson, M. T., Keer, L. M., Mechanics of edge effects on frictionless contacts. International Journal of Solids and Structures, 32, 1995, 391-405.

[6]. Slack, T., Sadeghi, F., Explicit finite element modeling of subsurface initiated spalling in rolling contacts. Tribology International, 43, 2010, 1693-1702.

[7]. Wang, L. Q., Ye, Z. H., Gu, L., The effect of roller profile modification on roller bearing performance. Advanced Materials Research, 230-232, 2011, 1210-1215.

[8]. Xia, X. T., Forecasting method for product reliability along with performance data, Journal of Failure analysis and Prevention, 12(10), 2012, 532-540.

[9]. Xia, X. T., Zhu, S, C., Jia, C. H., \& Niu, R. J., Contact stress analysis of cylindrical roller with logarithmic curve generatrix of convexity excursion. Journal of Henan University of Science and Technology, 33(5), 2012, 41-44. (in Chinese)

[10]. Xia, X. T., Zhu, S, C., Jia, C. H., \& Niu, R. J., Study of interval of arc modification length of cylindrical roller using ANSYS. RESEARCH INVENTY: International Journal of Engineering and Science, 1(1), 2012, 8-13.

[11]. Xia, X. T., Zhu, S, C., Jia, C. H., \& Niu, R. J., Analysis of contact stress between cylindrical roller and outer ring raceway with taper error using ANSYS. Modern Applied Science, 6(12), 2012, 86-90. 